\title{
HUBUNGAN ANTARA PENGETAHUAN DENGAN SIKAP DALAM MELAKUKAN PERAWATAN ALAT KELAMIN (VULVA HYGIENE) SAAT MENSTRUASI PADA REMAJA PUTRI KELAS XI DI SMA NEGERI 09 PONTIANAK TAHUN 2019
}

\section{Yuliana $^{1}$, Alexander ${ }^{2}$}

\author{
Akademi Kebidanan Panca Bhakti Pontianak \\ Email korespondensi: akbidpbpontianak@gmail.com
}

\begin{abstract}
Abstrak
Praktik kebersihan saat menstruasi pada remaja usia sekolah perlu mendapat perhatian. Pengetahuan yang kurang sesuai dan sikap yang tidak mendukung perawatan alat kelamin yang benar selama menstruasi dapat memicu terjadinya masalah kesehatan reproduksi seperti infeksi atau keputihan. Studi pendahuluan terhadap 20 orang siswi diketahui 12 orang siswi tidak mengetahui cara perawatan alat kelamin yang benar yaitu mengganti pembalut 2 kali sehari pada saat mandi saja, dan mengganti pembalut jika tembus tanpa dibasuh terlebih dahulu jika terjadinya gatal kemerahan di area pinggir vagina hanya memberikan salap pi kang shuang saja atau dibiarkansehingga menggalami infeksi (keputihan) 3 orang siswi dan 5 orang siswi mengatakan sering merah dibagian selangkangan pada saat menstruasi. Tujuan penelitian ini adalah mengetahui hubungan antara pengetahuan dengan sikap dalam melakukan perawatan alat kelamin (vulva hygaine) saat menstruasi pada remaja putri kelas X dan XI di SMA negeri 09 Pontianak. Penelitian ini menggunakan metode deskriptif korelasi dengan pendekatan cross sectional, teknik pengumpulan data menggunakan kuisioner dengan jumlah sampel sebanyak 99 remaja putri dengan teknik simple random sampling. Analisis data menggunakan analisis univariat untuk menguji pengetahuan dan sikap responden dan analisis bivariat untuk mengetahui hubungan antara variabel. Hasil penelitian univariat dengan distribusi frekuensi menunjukkan bahwa sebagian responden 61 remaja putri $(63,6 \%)$ berpengetahuan cukup tentang perawatan alat kelamin vulva hygiene pada saat menstruasi, kategori sikap menunjukkan bahwa 57 responden $(59,4 \%)$ memiliki sikap mendukung terhadap perawatan alat kelamin (vulva hygiene) saat menstruasi. Hasil analisis bivariat dengan distribusi X hitung 5,37 $>\mathrm{X}$ tabel tidak ada hubungan antara pengetahuan dengan sikap. Kesimpulan penelitian ini yaitu tidak ada hubungan antara pengetahuan dengan sikap dalam melakukan perawatan alat kelamin (vulva hygiene) pada saat menstruasi pada remaja putri kelas X dan XI di SMA negeri 09 Pontianak. Saran Agar pihak sekolah dapat bekerja sama dengan puskesmas daerah binaan wilayah pontianak timur untuk memberikan penyuhan tentang perawatan alat kelamin (vulva hygiene) pada saat menstruasi.
\end{abstract}

Kata Kunci: Pengetahuan, Sikap, Perawatan Alat Kelamin, Menstruasi, Remaja Putri

\begin{abstract}
Hygiene practices during menstruation in school-age teens need attention. Inadequate knowledge and attitudes that do not support proper genital care during menstruation can lead to reproductive health problems such as infection or vaginal discharge. A preliminary study of 20 female students found that 12 female students did not know how to properly care for the genitals, namely changing the pads 2 times a day while bathing, and changing pads if they were translucent without being washed first if red itching in the peripheral area of the vagina only provided pi kang shuang salve or just ignore it, so they have an infection (leucorrhoea). As many as 3 female students and 5 female students said often red in the groin during menstruation. The purpose of this study was to determine the relationship between knowledge and attitude in performing genital care (vulva hygiene) during menstruation in female teenager class X and XI in Negeri 09 Pontianak Senior High School. This study uses descriptive correlation method with cross sectional approach, data collection techniques using questionnaires with a sample of 99 female teenager with simple random sampling technique. Data analysis uses univariate analysis to test respondents' knowledge and attitudes and bivariate analysis to determine the relationship between variables. The results of univariate research with frequency distribution showed that some respondents of 61 female teenager $(63.6 \%)$ had sufficient knowledge about genital care of vulva hygiene during menstruation, the attitude category showed that 57 respondents $(59.4 \%)$ had a supportive attitude towards genital care (vulva hygiene) during menstruation. The results of bivariate analysis with the distribution of $\mathrm{X}$ arithmetic 5.37> X table there is no relationship between knowledge and attitude. The conclusion of this study is that there is no relationship between knowledge and attitude in performing genital care (vulva hygiene) during menstruation in female teenagers in class X and XI in Negeri 09 Pontianak Senior High School.
\end{abstract}

\footnotetext{
${ }^{1}$ Dosen Akademi Kebidanan Panca Bhakti Pontianak

${ }^{2}$ Dosen Akademi Kebidanan Panca Bhakti Pontianak
} 
Suggestions for schools to work together with regional health centers fostered in the East Pontianak area to provide information about genital care (vulva hygiene) during menstruation.

Keywords: Knowledge, Attitude, Gender Care, Menstruation, Female Teenager

\section{Pendahuluan}

Menstruasi merupakan titik awal proses reproduksi remaja putri yang memerlukan perawatan dan perhatian lebih agar remaja terhindar dari berbagai masalah kesehatan reproduksi (Vindari, 2011). Darah haid merupakan tempat yang ideal bagi pertumbuhan bakteri dan jamur penyebab keputihan dan infeksi. Kebersihan pada saat menstruasi juga sangat penting diperhatikan. Penyebab utama terjadinya penyakit infeksi saluran reproduksi yaitu: imunitas lemah (20\%), perilaku hygiene saat menstruasi kurang (30\%), dan penggunaan pembalut yang tidak sehat saat menstruasi (50\%) (Rahmatika, 2010).

Ketika seorang lalai dalam menjaga kebersihan organ intim khususnya ketika sedang menstruasi maka dapat menyebabkan tumbuhnya mikroorganisme yang tidak diharapkan. Kelalaian ini juga bisa menimbulkan bau, infeksi, juga keputihan yang tidak wajar (Pribakti, 2012). Pratik kebersihan saat menstruasi yang buruk menyebabkan seorang remaja beresiko 1,4 sampai dengan 25,07 kali terkena reproductive tract injection (RTI) (Sumpter and torondel, 2013).

World Health Organization (WHO) mengatakan bahwa 5\% remaja di dunia Pernah terjangkit Penyakit Menular Seksual (PMS) dengan gejala keputihan setiap tahunnya, bahkan di Amerika Serikat hal ini terjadi pada 1 dari 8 orang remaja. Di indonesia sekitar 90\% wanita mengalami keputihan karena negara indonesia adalah daerah beriklim tropis sehingga jamur mudah tumbuh dan berkembang sehingga mengakibatkan keputihan pada wainta (Badaryati, 2012). Faktor resiko umum untuk infeksi vagina yaitu kehamilan dan kebersihan yang buruk saat menstruasi (Geerthu, 2016). Berdasarkan Data SKKRI (2007) menunjukkan bahwa persentase perempuan usia 15 sampai 24 tahun mengalami keputihan sebanyak $31,8 \%$, ini menunjukkan bahwa remaja putri mempunyai resiko lebih tinggi mengalami keputihan.

Program kesehatan reproduksi remaja diintegrasikan dalam program kesehatan remaja di Indonesia. Sejak tahun 2003 kementerian kesehatan telah mengembangkan model pelayanan kesehatan peduli remaja (PKPR). Ciri khas pelayanan kesehatan peduli remaja adalah pelayanan konseling dan peningkatan kemampuan remaja dalam menerapkan pendidikan dan keterampilan hidup sehat (PKHS).

Pelayanan Kesehatan Peduli Remaja (PKPR) di hubungkan dengan kegiatan usaha kesehatan sekolah (UKS) dibina oleh puskesmas setempat. Hingga akhir tahun 2014 terdapat $81,69 \%$ Kabupaten/Kota yang memiliki 4 Puskesmas PKPR dan 2.999 dari 9.731 puskesmas (31\%) yang mampu melaksanakan PKPR. Pada akhir tahun 2019, 
ditargetkan $45 \%$ puskesmas di indonesia telah menyelenggarakan kegiatan kesehatan remaja.

Praktik kebersihan saat menstruasi pada remaja usia sekolah perlu mendapat perhatian. Pengetahuan yang kurang sesuai, serta batasan batasan yang dialam terkait dengan menstruasi dapat berdampak pada kesehatan, pendidikan maupun psikososial (Sumpter and Torondel, 2013).

Pengetahuan adalah hasil penginderaan manusia atau hasil tahu seseorang terhadap suatu objek dari indra yang dimilikinya (mata, hidung, telinga, dan sebagainya). Dengan sendirinya pada waktu pengindraan sampai menghasilkan pengetahuan tersebut sangat dipengaruhi oleh intensitas perhatian dan presepsi terhadap objek (Notoatmodjo, 2012). Pemahaman seseorang terhadap kesehatan reproduksinya sangatlah penting, seseorang yang tidak memiliki pengetahuan tentang respon yang cukup akan cenderung mengabaikan kesehatan reproduksinya dan resiko melakukan tindakan yang membahayakan bagi dirinya dengan tidak berprilaku hygiene dalam menjaga organ reproduksinya sendiri (Notoadmojo, 2005 dalam Rahma 2016).

Pengetahuan remaja tentang perawatan diri khususnya kebersihan alat kelamin saat menstruasi tergantung pada informasi yang diterimanya, sumber informasi tersebut dapat memberikan pengaruh jangka pendek sehingga membantu remaja mengalami peningkatan pengetahuan. Pemerintah mengintegrasikan program kesehatan reproduksi remaja dengan Metode Pelayanan Kesehatan Peduli Remaja (PKPR). Sejak tahun 2003, dalam bentuk pelayanan konseling dan peningkatan kemampuan remaja dalam menerapkan pendidikan dan keterampilan hidup sehat (PKHS). Seperti perawatan diri khususnya alat kelamin saat menstruasi.

Sikap merupakan reaksi atau respon yang masih tertutup dari seseorang terhadap suatu stimulasi atau objek. Disebutkan juga bahwa sikap itu merupakan kesiapan atau kesedian untuk bertindak dan juga merupakan pelaksanaan motif tertentu (Notoadmodjo (2003). Respon seseorang muncul dari informasi yang diterimanya atau diamatinya dimana dalam hal ini sikap remaja dalam melakukan praktik yang benar saat membersihkan alat kelamin selama menstruasi diharapkan dapat menerapkan resiko masalah kesehatan reproduksi seperti infeksi atau keputihan.

Kaitan atau hubungan antara pengetahuan dan sikap remaja dalam perawatan personal hygiene saat menstruasi di jabarkan dalam beberapa penelitian seperti Hasil penelitian Tranggono dkk dengan judul Gambaran Pengetahuan Sikap dan Perilaku menjaga kebersihan Organ Genetalia eksterna terhadap kejadian keputihan abnormal pada remaja putri Mts Al Gaot Siyah Jakarta barat tahun 2017 menyatakan bahwa 76,7\% responden memiliki pengetahuan yang buruk tentang kebersihan organ genetalia dan 37,5\% yang memiliki sikap baik terhadap kebersihan organ genetalia. 
Rendahnya pendidikan dan kurangnya informasi yang diperoleh mengenai kesehatan reproduksi mengakibatkan siswi tidak mengetahui betapa pentingnya dan bagaimana cara yang baik dalam menjaga kebersihan genetalia di pengaruhi faktor lingkungan kebudayaan. Pengalaman pribadi sumber informasi serta pengaruh media massa.

Penelitian yang dilakukan oleh Dwi Rahmatika yang berjudul Pengetahuan dan Sikap Tentang Personal Hygiene Menstruasi Terdapat Personal Hygiene Remaja Putri Pada Saat Menstruasi Di SMK Negeri 8 Medan Tahun 2010. Berdasarkan uji chi square didapatkan hasil bahwa ada pengaruh atau hubungan pengetahuan tentang personal hygiene menstruasi terdapat perilaku personal hygiene remaja putri pada saat menstruasi dengan nilai $\mathrm{p}=0,022^{19}$. Bahwa semakin tinggi tingkat pengetahuan remaja putri tentang personal hygiene pada saat menstruasi maka semakin tinggi pula remaja putri tersebut berperilaku baik terhadap personal hygiene nya pada saat menstruasi dan sebaliknya.

Tidak semua sekolah menjadi mitra program PKPR seperti yang terjadi di SMA Negri 09 Pontianak. Hasil studi pendahuluan yang dilakukan peneliti diketahui bahwa SMA Negri 09 Pontianak adalah salah satu sekolah yang tidak masuk dalam program pelayanan kesehatan reproduksi remaja (PKRK) dan juga tidak pernah mendapatkan kunjungan dari puskesmas terdekat, terkait dengan informasi kesehatan reproduksi yang di dapatkan oleh siswi hanya pada pelajaran biologi saja.
Berdasarkan studi pendahuluan yang dilakukan pada tanggal 26 Febuari 2019 di SMA Negeri 09 Pontianak, jumlah total keseluruhan siswa kelas XI yaitu 245 siswa yang terdiri dari 114 orang remaja putra dan 131 orang remaja putri. Hasil wawancara peneliti terhadap 20 orang siswi remaja putri didapatkan hasil bahwa 12 orang siswi tidak mengetahui cara perawatan alat kelamin yang benar sehingga menggalami infeksi (keputihan) 3 orang siswi dan 5 orang siswi mengatakan sering merah dibagian selangkangan pada saat menstruasi.

Cara perawatan alat kelamin saat menstruasi yang dilakukan 20 remaja putri antara lain mereka hanya mengganti pembalut 2 kali sehari pada saat mandi saja, dan mengganti pembalut jika tembus tanpa dibasuh terlebih dahulu jika terjadinya gatal kemerahan di area pinggir vagina hanya memberikan salap pi kang shuang saja atau dibiarkan.

Masih kurangnya informasi kesehatan reproduksi khususnya perawatan alat kelamin oleh remaja putri saat menstruasi di SMA Negeri 09 Pontianak dan cara perawatan alat kelamin yang tidak higenis sehingga berdampak pada infeksi (keputihan) bagaimanakah manarik peneliti untuk hubungan pengetahuan dan sikap dalam melakukan perawatan alat kelamin (vulva hygiene) saat menstruasi pada remaja putri kelas X di SMA Negeri 09 Pontianak.

\section{Metode}

Penelitian ini menggunakan jenis 
penelitian deskriptif korelasional dengan pendekatan cross sectional. Penelitian dilaksanakan pada bulan Februari hingga Juni 2019 di SMA Negeri 09 Pontianak. Populasi penelitian yaitu seluruh remaja putri siswi kelas XI berjumlah 131 orang. Sampel menggunakan rumus Slovin sebanyak 99 orang.

Peneliti menggunakan simple random sampling dengan menetapkan proporsi sebagai perwakilan dari 7 kelas dengan distribusi kelas XI matematika 1, 2 dan 3 masing-masing 18 siswi, kelas XI ilmu alam 1, 2 dan 4 masing-masing 11 siswi dan kelas XI ilmu alam 3 sebanyak 9 siswi. Pengumpulan data menggunakan kuesioner kemudian diolah dan dianalisis menggunakan analisis univariat serta analisis bivariat menggunakan uji chi square.

\section{Hasil dan Pembahasan}

Pada saat pelaksanaan penelitian dari 99 responden yang ditetapkan , 3 orang responden atau siswi tidak hadir dikarenakan sakit sehingga jumlah responden yang diteliti tersisa 96 orang. Setelah dilakukan penelitian terhadap 96 responden yaitu remaja putri kelas XI di SMA Negeri 09 Pontianak tahun 2019 tentang pengetahuan dan sikap remaja dalam melakukan perawatan alat kelamin (vulva hygiene) saat menstruasi" diperoleh hasil sebagai berikut:

Tabel 1 Pengetahuan Responden tentang perawatan alat kelamin saat menstruasi

\begin{tabular}{lcc}
\hline \multicolumn{1}{c}{ Pengetahuan Responden } & \multicolumn{2}{c}{ Jumlah } \\
\cline { 2 - 3 } & $\mathrm{N}$ & $\%$ \\
\hline Pengetahuan Baik & 20 & 20,8 \\
Pengetahuan Cukup & 61 & 63,6 \\
Pengetahuan Kurang & 15 & 15,6 \\
\hline
\end{tabular}

Dari tabel 1 dapat disimpulkan bahwa sebagian besar dari responden yaitu 61 responden $(63,6 \%)$ memiliki pengetahuan cukup dan sangat sedikit dari responden 15 respoden $(15,6 \%)$ memiliki pengetahuan kurang tentang perawatan alat kelamin vulva hygiene pada saat menstruasi. Dari hasil penelitian banyak responden menjawab salah soal no 11 , terbukti pada pertanyaan tentang cara membersihkan alat kelamin selama menstruasi hanya 4 responden yang menjawab benar dan 92 responden menjawab salah, dimana responden menjawab perawatan alat kelamin yang benar harus menggunakan cairan daun sirih.

Menurut peneliti hal ini disebabkan oleh kurangya informasi mengenai kesehatan reproduksi baik dari pihak sekolah tentang perawatan alat kelamin dan tidak adanya kunjungan dari pihak pelayanan kesehatan seperti Puskesmas atau kunjungan dari pihak institusi pendidikan kesehatan yang memilih sekolah sebagai tempat pengabdian masyarakat dalam bentuk penyuluhan kesehatan sehingga informasi yang dimiliki oleh remaja putri tentang cara perawatan alat kelamin saat menstruasi sangat beragam dan 
tidak dapat dievaluasi apakah perawatan tersebut benar atau tidak sehingga banyak responden yang menjawab salah tentang peralatan yang digunakan saat membersihkan alat kelamin.

Hal ini sesuai dengan teori yang disampaikan oleh Notoadmodjo (2010) yang menyatakan bahwa pengetahuan adalah hasil pengindraan manusia, atau hasil tahu seseorang terhadap objek melalui indera yang dimilikinya (mata, hidung, telinga,dan sebagainya). Tidak adanya stimulus atau rangsangan terhadap indera diatas mengenai kesehatan reproduksi khususnya perawatan alat kelamin selama menstruasi tentunya berpengaruh terhadap kategori pengetahuan yang dimiliki.

Hasil penelitian ini sama dengan hasil penelitian yang dilakukan oleh Ajeng Setianingsih, yang berjudul 'Hubungan Pengetahuan dan Sikap Terhadap Personal hygiene menstruasi di SMP Patriot Kranji tahun 2016" di dapatkan hasil bahwa pengetahuan responden tergolong kurang 47 responden $(46,1 \%)$.

Perbedaan hasil penelitian ini dengan penelitian diatas menurut peneliti dikarenakan kategori responden yang berbeda khususnya secara usia dimana penelitian Ajeng dilakukan pada remaja putri SMP (remaja awal) sehingga pengalaman tentang menstruasi mungkin merupakan peristiwa baru bagi remaja sehingga pengetahuan remaja cenderung kurang sedangkan penelitian ini pada remaja putri SMA (remaja tengah) yang mempunyai pengalan menstruasi lebih banyak dibandingkan remaja awal (SMP) sehingga hasil penelitian lebih banyak menemukan pengetahuan dengan kategori cukup dan baik.

Pendekatan pihak sekolah dengan Institusi pelayanan kesehatan untuk pemberian informasi tentang cara perawatan alat kelamin saat menstruasi perlu dilakukn sehingga informasi yang dimiliki oleh remaja putri/ siswinya adalah informasi yang benar dan tepat.

Tabel 2 Sikap Responden dalam melakukan perawatan alat kelamin saat menstruasi

\begin{tabular}{lccc}
\hline & \multirow{2}{*}{ Sikap } & \multicolumn{2}{c}{ Jumlah } \\
\cline { 2 - 4 } & & $\mathrm{N}$ & $\%$ \\
\hline Mendukung & 57 & 59,4 \\
Tidak Mendukung & 39 & 40,6 \\
\hline
\end{tabular}

Berdasarkan tabel 2 data yang di peroleh dari 96 reponden dapat disimpulkan bahwa sebagian responden 39 responden $(40,6 \%)$ memiliki sikap tidak mendukung dan sebagian dari responden 57 responden $(59,4 \%)$ memiliki sikap mendukung terhadap perawatan alat kelamin (vulva hygiene) saat menstruasi. memiliki sikap mendukung dalam melakukan perawatan alat kelamin lebih tinggi dibandingkan dengan yang tidak mendukung dikarenakan pengetahuan remaja yang cukup tentang cara melakukan perawatan alat kelamin sehingga mengarahkan remaja dalam bersikap dalam melakukan perawatan. 
Pengalaman tentang menstruasi yang dialami remaja putri juga turut membentuk sikap responden, dimana sampai dengan penelitian dilakukan remaja sudah mengalami menstruasi lebih dari $1 \mathrm{x}$ sehingga responden dapat melakukan perawatan alat kelamin saat menstruasi terlepas perawatan itu salah atau benar dari sisi kesehatan. Hal ini sesuai dengan teori yang disampaikan oleh Azwar 2011 yang menyatakan bahwa pengalaman pribadi merupakan salah satu faktor pembentuk sikap dimana supaya menjadi suatu sikap yang mendorong perilaku dperlukan perngalaman pribadi yang meninggalkan kesan kuat dan terjadi berulang. Dalam penelitian ini pengalaman tentang menstruasi yang sudah sering dialami oleh remaja putri akan mengarahkan remaja pada sikap mendukung melakukan perawatan alat kelamin yang benar.

Hasil penelitian ini sesuai dengan hasil penelitian yang dilakukan oleh Maria Hariyati Butar-Butar tahun 2016, yang berjudul 'Hubungan Pengetahuan dan Sikap dengan tindakan remaja putri tentang Personal hygiene saat menstruasi di SMA Negeri 1 Sitinjak Kecamatan Angkola Barat tahun 2016" di dapatkan hasil bahwa dari 129 ditemukan sebanyak 44 responden $(55,6 \%)$ bersikap baik/mendukung dalam melakukan personal hgyiene dan perawatan alat kelamin selama menstruasi. Evaluasi rutin oleh guru bimbingan konseling bekerja sama dengan guru mata pelajaran biologi tentang cara perawatan alat kelamin perlu dilakukan oleh pihak sekolah.

Tabel 3 Pengetahuan dan sikap dalam melakukan perawatan alat kelamin saat menstruasi pada remaja putri kelas XI di SMA Negeri 09 Pontianak tahun 2019

\begin{tabular}{cccccccc}
\hline \multirow{2}{*}{ Pengetahuan } & \multicolumn{5}{c}{ Sikap } & \multirow{2}{*}{ X } & \multirow{2}{*}{ X Tabel } \\
\cline { 2 - 5 } & \multicolumn{2}{c}{ Tidak mendukung } & \multicolumn{2}{c}{ Mendukung } & Hitung & \\
\cline { 2 - 5 } & $\mathrm{N}$ & $\%$ & $\mathrm{~N}$ & $\%$ & & \\
\hline Kurang & 10 & 66,7 & 5 & 33,3 & 5,37 & 5,991 \\
Cukup & 21 & 33,9 & 41 & 66,1 & & \\
Baik & 8 & 42,1 & 11 & 57,9 & & \\
\hline
\end{tabular}

Berdasarkan tabel 3 tentang tabel silang pengetahuan dan sikap responden dalam melakukan perawatan alat kelamin saat menstruasi diketahui bahwa sebagian besar dari responden yaitu 10 orang $(66,7 \%)$ yang berpengetahuan kurang memiiki sikap tidak mendukung melakukan perawatan alat kelamin saat menstruasi.

Sebagian kecil dari responden yaitu 5 orang $(33,3 \%)$ yang berpengetahuan kurang memiiki sikap mendukung melakukan perawatan alat kelamin saat menstruasi. Sebagian kecil dari responden yaitu 21 orang $(33,9 \%)$ yang berpengetahuan cukup memiiki sikap tidak mendukung melakukan perawatan alat kelamin saat menstruasi. Sebagian besar dari responden yaitu 41 orang $(66,1 \%)$ yang berpengetahuan cukup memiiki sikap mendukung melakukan perawatan alat kelamin saat menstruasi.

Sebagian dari responden yaitu 8 orang $(42,1 \%)$ yang berpengetahuan baik memiiki 
sikap tidak mendukung melakukan perawatan alat kelamin saat menstruasi. Sebagian dari responden yaitu 11 orang $(57,9 \%)$ yang berpengetahuan baik memiiki sikap mendukung melakukan perawatan alat kelamin saat menstruasi.

Pada penelitian ini $\mathrm{X}^{2}$ hitung $>\mathrm{X}^{2}$ tabel yang artinya $\mathrm{Ha}$ di tolak dan Ho di terima karna $\mathrm{X}^{2}$ hitung lebih kecil dari $\mathrm{X}^{2}$ tabel. Dari hasil uji statistik didapatkan kesimpulan tidak ada Hubungan pengetahuan dengan sikap dalam melakukan perawatan alat kelamin (vulva hygiene) saat menstruasi pada remaja putri kelas XI di SMA Negeri 09 Pontianak tahun 2019.

Menurut peneliti hal ini sesuai dengan teori Notoadmodjo (2010), bahwa sebagian besar pengetahuan seseorang diperoleh melalui indra pendengaran (telinga) dan indra penglihatan (mata) pengetahuan seseorang terhadap objek mempunyai intensitas atau tingkat yang berbeda - beda. Teori Notoadmodjo (2013) mengatakan bahwa pengetahuan seseorang dapat dipengaruhi oleh faktor informasi. Informasi dan pengalaman akan menambah pengetahuan remaja tentang perawatan alat kelamin (vulva hygiene) pada saat menstruasi

Respon seseorang muncul dari informasi yang diterimanya atau diamatinya dimana dalam hal ini sikap remaja dalam melakukan praktik yang benar saat membersihkan alat kelamin selama menstruasi diharapkan dapat menerapkan resiko masalah kesehatan reproduksi seperti infeksi atau keputihan. Dalam penelitian ini terlihat jelas bahwa semakin baik pengetahuan remaja putri maka sikap yang ditunjukkan dalam perawatan alat kelamin juga mendukung.

Menurut Azwar 2011 sikap dibentuk oleh pengalaman pribadi seseorang, pengalaman remaja putri kelas XI dengan usia 15-16 tahun akan mengarahkan remaja pada sikap yang mendukung dan memudahkan penerimaan informasi dari berbagai sumber tentang perawatan alat kelamin yang bisa didapat dari media massa, orang terdekat dalam hal ini sosial budaya maupun lingkungan sosial seperti orang tua atau saudara perempuannya.

Hasil penelitian berbeda dengan penelitian yang dilakukan oleh Dwi Rahmatika yang berjudul Pengetahuan dan Sikap Tentang Personal Hygiene Menstruasi Terdapat Personal Hygiene Remaja Putri Pada Saat Menstruasi Di SMK Negeri 8 Medan Tahun 2010. Berdasarkan uji chi square didapatkan hasil bahwa ada pengaruh atau hubungan pengetahuan tentang personal hygiene menstruasi terdapat perilaku personal hygiene remaja putri pada saat menstruasi dengan nilai $\mathrm{p}=0,022^{19}$.

Berbeda dengan hasil yang dilakukan pada penelitian ini yaitu Berdasarkan analisis $\mathrm{X}^{2}$ 5,37 < 5,991 maka Ha ditolak dan Ho diterima sehingga dapat disimpulkan bahwa tidak ada Hubungan pengetahuan dan sikap dalam melakukan perawatan alat kelamin (vulva hygiene) saat menstruasi pada remaja putri kelas XI di SMA Negeri 09 Pontianak tahun 2019.

Walaupun jurnal statistik tidak ada hubungan namun data yang di peroleh peneliti 
bahwa pengetahuan responden tidak sesuai dengan sikap responden. Pengetahuan responden dalam penelitian ini terbanyak dalam kategori cukup hal ini dikarenakan informasi lisan yang diperoleh tidak ada dari sumber yang tepat (tenaga kesehatan) sedangkan demonstrasi tentang cara perawatan alat kelamin tidak pernah diterima dari pihak sekolah. Meskipun sikap remaja putri mendukung melakukan perawatan alat kelamin, namun sikap belumlah sebuah perilaku kesehatan sehingga terlihat jelas dalam penelitian ini tidak ditemukan hubungan secara statistik antara pengetahuan dan sikap.

Pemberian informasi yang tepat oleh sumber yang benar dapat mengubah pengetahuan remaja putri ke arah yang baik sehingga mempunyai sikap yang mendukung dalam melakukan perawatan alat kelamin dan nantinya dapat merubah perilaku remaja kearah yang benar dalam melakukan perawatan alat kelamin, perlu diberikan kerja sama pihak sekolah dengan pihak kesehatan atau menjadi bagian dari program PKRK dapat membantu meningkatkan status kesehatan reproduksi remaja khususnya sebagai bentuk pembelajaran terhadap penyakit infeksi sperti keputihan.

\section{Kesimpulan}

Pengetahuan dalam Perawatan alat kelamin (vulva hygiene) yaitu sebagian besar dari responden yaitu 61 responden $(63,6 \%)$ memiliki pengetahuan cukup. Didapatkan 57 responden $(59,4 \%)$ memiliki sikap mendukung menjaga perawatan alat kelamin (vulva hygiene) pada saat menstruasi. Hubungan antara pengetahuan dengan sikap didapat tidak ada hubungan antara pengetahuan dengan sikap dalam melakukan perawatan alat kelamin (vulva hygiene) pada saat menstruasi pada remaja putri kelas xi di SMA Negeri 09 pontianak tahun 2019 dengan $\mathrm{X}^{2}$ hitung 5,37> $\mathrm{X}^{2}$ tabel 5,991 yang artinya Ha di tolak dan Ho di terima. Saran Agar pihak sekolah dapat bekerja sama dengan puskesmas daerah binaan wilayah pontianak timur untuk memberikan penyuhan tentang perawatan alat kelamin (vulva hygiene) pada saat menstruasi.

\section{Daftar Pustaka}

Azwar,S.2010. Sikap Manusia Teori dan Pengukurannya. Yogyakarta: Pustaka Pelajar

Budiman \& Riyanto A.2013. Kapita Selekta Kuesioner Pengetahuan Dan Sikap Dalam Penelitian Kesehatan. Jakarta: Selemba Medika pp 66-69

Butarbutar, m. h. (2016). Hubungan Pengetahuan dan Sikap Dengan Tindakan Remaja Putri Tentang Personal Hygiene Saat Menstruasi di SMA Negeri I Sitinjak Kecamatan Angkola Barat Tahun 2016

Gerungan. (2009). Psikologi Sosial. Bandung: PT Refika Aditama

Kumalasari I. 2012.Kesehatan Reproduksi. Jakarta: Rineka Cipta

Notoatmodjo, S. 2007. Promosi Kesehatan Masyarakat dan Ilmu Perilaku. Jakarta: Rineka cipta

Notoatmodjo S. 2012. Metodelogi Penelitian Kesehatan. Jakarta: Rineka Cipta

Prabakti, 2012. Epidemiologi Penyakit 
Menular Seksual (PMS). Jakarta: Balai Penerbit FKUI

Sarwono, S. 2011. Psikologi Remaja. Jakarta: PT. Raja Grafindo

Sumadi,B. 2013. Budidaya Intensif Kaitan
Secara Organik dan Anorganik. Jakarta: Pustaka Mina.

Wijayanti , D. (2009). Fakta Penting Seputar Kesehatan Reproduksi Wanita Jogjakarta: Book Marks 